Discussion Paper Series A No.419

Optimal Executive Compensation:

Some Equivalence Results

Chongwoo Choe

(Australian Graduate School of Management,

University of New South Wales and

University of Sydney, Australia/

The Institute of Economic Research, Hitotsubashi University)

December 2001 


\title{
Optimal Executive Compensation: Some Equivalence Results*
}

\author{
Chongwoo Choe
}

\author{
Australian Graduate School of Management \\ University of New South Wales and University of Sydney
}

Please send all correspondence to:

Chongwoo Choe

Australian Graduate School of Management

University of New South Wales

Sydney, NSW 2052, AUSTRALIA

(Phone) +61 299319528

(Fax) +61 293137279

(Email) c.choe@agsm.edu.au

* I would like to thank Bernardino Adão, Aloisio Araujo, Yeon-Koo Che, Gerald Garvey, and seminar participants at the Australian Graduate School of Management, the Australian National University, the Bank of Portugal, La Trobe University, the University of Bristol, the University of Exeter, the University of Melbourne, the University of Sydney, Universidade Católica Portuguesa and Universidade Nova de Lisboa for helpful comments. I am especially thankful to Ian Jewitt and In-Uck Park for their incisive comments, and to the Bank of Portugal for financial support. The usual disclaimer applies. 


\title{
Optimal Executive Compensation: Some Equivalence Results
}

\begin{abstract}
This paper studies optimal managerial contracts in two contracting environments. When contracts can be based on earnings, an optimal contract is interpreted as a combination of base salary, golden parachute and bonus. When earnings are not verifiable, two types of optimal contracts are derived: a contract with restricted stock ownership, and a contract with stock options. These three types of optimal contracts are payoff-equivalent in a strong sense: agents' ex ante and ex post payoffs are the same under all three contracts, implying that the choice of contractual form is irrelevant in the environment studied in this paper. This paper thus suggests directions of research for the relevance of different contractual forms.
\end{abstract}

KEY WORDS: Optimal contract, executive compensation, bonus, golden parachutes, stock ownership, stock options.

JEL CLASSIFICATION: D82, G32, J33. 


\section{Introduction}

For some time, the magnitude of compensation for corporations' chief executive officers (CEOs) has spawned heated debate among academics and the public alike. ${ }^{(1)}$ While public outcry regarding the astronomical figures may still exist, it seems that the debate has waned at least among academics. Academic interests in CEO compensation have taken different turns. Some of the major issues now are the discrepancy between theory and practice, and the way CEOs ought to be paid.

The main point regarding the first issue is how economic theory of contract fails to explain the small pay-performance sensitivity of CEO compensation. While there is no consensus whether the empirical pay-performance sensitivity of executive compensation is as prescribed by the principal-agent theory, ${ }^{(2)}$ there is convincing evidence that incentive effects of stock options or stock ownership far outweigh those of cash compensation. For example, Jensen and Murphy (1990a) report that the pay-performance sensitivity for CEOs represented by stock options is more than 30 times than that by cash compensation. Hall and Liebman (1998) find that a strong positive relationship between firm performance and CEO compensation is mostly due to CEO holdings of stocks and stock options, with the incentive effects from stock and stock option revaluations being 53 times larger than those from salary and bonus changes.

This paper is mainly concerned with the second issue. In particular, we are interested in two questions. First, why are incentives to executives provided more and more through stocks and stock options rather than through conventional bonus? ${ }^{(3)}$ In addressing this question, we take the opposite direction and identify an environment in which different incentive schemes can generate the same incentives. This enables us to identify a host of factors that are likely

(1) See, for example, Jensen and Murphy (1990b), Milgrom and Roberts (1992), Ch. 13 or Murphy (1999) and various references therein.

(2) Initial debate started with a seminal article by Jensen and Murphy (1990a). The low pay-performance sensitivity reported by Jensen and Murphy was explained by a parametrized principal-agent model by Haubrich (1994). Instead of using the level of executive compensation, Garen (1994), and Aggarwal and Samwick (1999) used the comparative static predictions of principal-agent model to explain the variations in pay-performance sensitivity across the cross section of firms. Hadlock and Lumer (1997), and Holderness et al. (1999) provide historical evidence on executive compensation. Using proxies for incentive effects of executive stock options, Hall and Liebman (1998), and Hall (1998) provide evidence for strong pay-performance sensitivity. For a survey, see Murphy (1999).

(3) This is most prominent in the US although the increasing use of stock options to motivate CEOs is highly visible in other industrialized economies as well. See Murphy (1999) for example. 
determinants of this changing trend. Second, what is the nature of relationship among various components that comprise a CEO compensation package? A typical CEO compensation package for large US corporations comprises cash salary and bonus, stock ownership, stock options and a provision for severance payment. ${ }^{(4)}$ Clearly these components are interrelated in motivating CEOs to act in the interests of shareholders. For example, the severance payment, or golden parachutes, is intended to induce the CEO to make proper decisions based on available information and not to distort the running of the firm to fight takeover bids. The opportunity cost for the CEO in taking this course of action is the compensation from continuation of appointment that might be lost after the takeover. It thus follows that golden parachutes should reflect this opportunity cost.

This paper studies a parsimonious model in which the components of CEO compensation package mentioned above can be introduced most naturally. The simple three-period model we study has two economic agents one of whom is called the owner and the other, the manager. The owner has an investment project and capital to finance it, but only the manager has the expertise to assess the profitability of the project. Initially, the owner hires a manager who then privately studies the profitability, which is modelled as the process of information acquisition. In period 2, the manager decides whether or not to undertake the project, or equivalently, the owner decides based on the report by the manager. If the project is aborted, then the manager leaves at a severance payment. If the project is undertaken, the return is realized and publicly observed in period 3 , based on which the manager is paid.

We study two environments and derive optimal contracts. First, if the return is verifiable also so that the initial contract can be based on the return, then the optimal contract is interpreted as a combination of golden parachute (payment at period 2 to the leaving manager), base salary and bonus (payment at period 3). In the second environment, we assume that the return is not verifiable, hence cannot be contracted upon. Nonetheless, it is publicly observable, and is reflected in the 'price' of the project. In this case, we derive two types of optimal contracts: a contract with stock ownership that is restricted to be traded only at date 3 , and a

(4) For more details on executive compensation in practice, see, for example, Kole (1997) or Murphy (1999) for a variety of incentive compensation plans adopted by US corporations. From a sample of 446 firms that appeared on the Forbes magazine list of the largest US firms in 1987, Agrawal and Knoeber (1998) find that the CEOs of 51 percent of these firms had golden parachutes (a severance agreement granting cash and other benefits if the CEO is fired, demoted, or resigns within a certain time period following the change in control). 
contract with stock options. These three types of optimal contracts are payoff-equivalent in a strong sense: managers' ex ante and ex post payoffs are the same under all three contracts. The intuition is simple. Insofar as the market correctly expects the investment decision implied by the managerial contract, which is impounded in the price of the project along with firm-level information that is observed noise-free, it is irrelevant whether incentives are provided based on firm-level information or market-based information. Or course, such irrelevance is subject to a requirement that the manager's trading in stocks or options be optimally timed. The paper thus shows how different types of contracts can replicate exactly the same incentives as long as they are designed optimally.

At first sight, one might think that the result of this paper is more negative than positive. A strong message from the paper, for example, is the irrelevance of using different forms of contracts as long as they are designed optimally. Accordingly, the question of why a certain type of contract is used more often than others remains unanswered. In the spirit similar to Modigliani and Miller propositions, what the result of this paper is pointing at is not so much the irrelevance of different forms of contracts per se, but rather the conditions that would make the question of relevance meaningful. For example, special features of the simple model studied in this paper include risk neutrality of managers, dichotomous and bulky investment, absence of moral hazard from other employees, absence of earnings manipulation by managers, perfect observability of earnings by markets, and efficient stock markets where public information is reflected perfectly in stock prices. Thus, a message from this paper is that the question of relevance is meaningful when one or more of these conditions are relaxed. In the concluding section of this paper, we discuss how the irrelevance result of this paper is likely to change when these conditions are relaxed.

The rest of this paper is organized as follows. Section 2 reviews the related literature. Section 3 describes a basic model. Section 4 studies an optimal contract in an environment where the return from the project is verifiable. Section 5 is concerned with a contracting environment where the return from the project is not verifiable. Two types of optimal contracts are derived: a contract with restricted stock ownership, and a contract with stock options. Section 6 summarizes the main results of the paper and discusses possible extensions of the model. Proofs not provided in the main text are all relegated to the appendix. 


\section{Related Literature}

This paper overlaps with several strands of literature in accounting, economics and finance. A bulk of papers in accounting have been concerned with the incentive aspect of managerial contracts based on either reported accounting earnings or stock price. Some examples are Bushman and Indjejikian (1993), Kim and Suh (1993), Sloan (1993), and Baiman and Verrecchia (1995) on the analysis of optimal contract, and Healy (1985) with numerous follow-up empirical studies on the possibility of earnings manipulation by managers when their bonus plan is based on accounting earnings. Depending on how private information is impounded in stock price, the first set of studies typically analyzes an optimal contract that is linear in earnings report and stock price. The linearity of an optimal contract rests on the normality of relevant random variables, and is justified in line with Holmström and Milgrom (1987). Paul (1992), and Holmström and Tirole (1993) study the optimality of linear stock-based contracts when the market's observation of firm-level information is not perfect. The present paper differs from these studies in providing a broad benchmark for the irrelevance of contractual forms, including contracts with stock ownership and stock options. As a consequence, we contend that elements such as information content of earnings or the possibility of earnings manipulation are but a few of many that could make the question of relevance meaningful.

The second strand of literature related to the present study is that on golden parachutes. Positive explanations for the use of golden parachutes offered previously include incentive alignment effect by Lambert and Larcker (1985), deferred payment effect by Knoeber (1986), bargaining advantage effect by Harris (1990), and commitment effect by Cyert and Kumar (1996) and Choe (1998). ${ }^{(5)}$ While the explanation provided in this paper is similar to those in Lambert and Larcker, and Choe, an additional insight is offered as to how golden parachutes are related to other components of CEO compensation package. In a simplified model of this paper, the size of golden parachute is the same regardless of whether performance incentives are provided through bonus, stock ownership or stock options.

Finally, the second half of this paper can be viewed as an application of incomplete contract

(5) For empirical evidence on the relationships between the adoption of golden parachutes, stock price reactions, and the incidence of takeovers, see Walking and Long (1984), Lambert and Larcker (1985), Agrawal and Knoeber (1998), and Narayanan and Sundaram (1998). 
theory to executive compensation. The single most important focus of incomplete contract theory has been on the resolution of holdup problem: the problem of underinvestment due to the incompleteness of contracts and the specificity of investment (Williamson, 1985; Hart and Moore, 1988). ${ }^{(6)}$ There is now extensive literature concerned with overcoming the holdup problem by adding option-like features to the initial contract, ${ }^{(7)}$ or by allowing renegotiation. ${ }^{(8)}$ Incomplete contracting approach has also been applied to explain the use of financial contracts different from standard debt or equity (Aghion and Bolton, 1992), or the stage financing feature of venture capital contracts (Repullo and Suarez, 1999). In a sense, this paper is also concerned with the resolution of holdup problem: the manager can learn the profitability of project at private cost, which cannot be directly contracted upon. Apart from the applied nature of questions addressed, this paper offers another solution to the holdup problem different from option-like features or simple contract combined with renegotiation possibility. That is, when the ownership rights can be traded in a market which correctly reflects public information in the price of ownership, then ownership itself can solve the holdup problem.

\section{Information Acquisition and Optimal Investment Decision}

The model has a representative shareholder called the owner and a continuum of ex ante identical managers. The owner is identified with a financier who has an investment project. However, only managers have expertise to assess the profitability of the project, and if it is found positive, to implement the project. The project requires an outlay $K$, and returns $\pi_{g}$ in a good state $(G)$ to be called 'success', and $\pi_{b}$ in a bad state $(B)$ to be called 'failure', with $\pi_{g}>K>\pi_{b} \geq 0$. The prior probability of success is commonly held to be $\gamma \in(0,1)$. Net interest rate is assumed to be zero, and all agents' reservation utilities are also normalized to zero. Finally, all agents are assumed to be risk neutral, interested only in maximizing

(6) The literature on legal remedies for breach of contracts predicts overinvestment in the presence of expectation damages remedy. See Edlin and Reichelstein (1998).

(7) Some of these studies are Demski and Sappington (1991), Hermalin and Katz (1993), Nöldeke and Schmidt (1995, 1998), Bernheim and Whinston (1998), and Edlin and Hermalin (1998).

(8) See Hart and Moore (1988), Chung (1991), MacLeod and Malcomson (1993), Aghion et al. (1994), and Edlin and Reichelstein (1996). With the possibility of renegotiation, Che and Hausch (1999) point out the difficulty of overcoming the holdup problem when specific investment is cooperative in nature. 
expected payoffs. Assuming risk neutrality allows us to separate the risk-sharing aspect from the incentive aspect of optimal contracts. The implication of relaxing this assumption will be discussed as we go on.

Before the project choice decision is made, managers alone can observe a signal $s \in$ $\left[s_{1}, s_{2}\right] \subset \mathbb{R}^{1}$ which has a conditional density function $f(s \mid \theta)$ and a conditional distribution function $F(s \mid \theta)$ for $\theta=G, B$. This signal observation, or information acquisition, is a primary task of the manager, which incurs private cost $c$ to the manager. ${ }^{(9)}$ One can think of this cost as a monetary equivalent of the manager's time and effort in assessing the profitability of the project. If a manager observed a signal $s$, we will refer to him as the manager of type s. Without information acquisition, managers share the same information as the owner, i.e., the prior probabilities. Given the signal observation, the marginal density function of signals is denoted by $f(s)=\gamma f(s \mid G)+(1-\gamma) f(s \mid B)$ and the distribution function by $F(s)$. Posterior probabilities are then $\operatorname{Pr}(G \mid s)=\frac{\gamma f(s \mid G)}{f(s)} \equiv p(s)$, and $1-p(s)=\frac{(1-\gamma) f(s \mid B)}{f(s)}$. Thus, $p(s)$ is the posterior probability of success for the type $s$ manager. All density functions are assumed to be differentiable and satisfy the following assumption.

Assumption 1: $f(s \mid \theta)$ satisfies the monotone likelihood ratio condition, i.e., $\frac{f(s \mid G)}{f(s \mid B)}$ is increasing in $s$.

As usual, assumption 1 means that a higher value of signal is more indicative of success. In particular, it implies that the conditional distribution $F(\cdot \mid G)$ dominates $F(\cdot \mid B)$ in the sense of first-order stochastic dominance. This assumption leads to the following lemma.

Lemma 1: (a) The posterior probability of success is strictly increasing in $s$, i.e., $p^{\prime}(s)>$ 0 ; (b) There exists a unique $s^{*} \in\left(s_{1}, s_{2}\right)$ such that $p\left(s^{*}\right)=\gamma$.

The net present value from the project under the prior belief is $\gamma \pi_{g}+(1-\gamma) \pi_{b}-K$

(9) We do not model the manager's or other employees' effort subsequent to the choice of project. This simplification is justified on two grounds. First, given other assumptions of our model, incorporating this type of moral hazard will not change the qualitative results of this paper. For instance, the effort variable can be introduced in an additively, separable way to the return as, for example, in Rogerson (1997). Second, we view the main role of managers as that of setting directions based on superior information they possess. To quote Jensen and Murphy (1990a, p. 251), "Managers often have better information than shareholders and boards in identifying investment opportunities and assessing the profitability of potential projects; indeed, the expectation that managers will make superior investment decisions explains why shareholders relinquish decision rights over their assets by purchasing common stocks". 
which is assumed to be zero. Thus the owner is not sure whether or not to go ahead with the project. Given the signal $s$, the net present value from the project under the posterior belief is $p(s) \pi_{g}+(1-p(s)) \pi_{b}-K$. By Lemma 1, we have $p\left(s^{*}\right)-\gamma=0$ and $p(s)-\gamma>0$ for all $s>s^{*}$. In the first-best world, information acquisition should thus lead to a cutoff rule for an optimal project choice: undertake the project if and only if $s \geq s^{*}$.

Then what is the value of information? If managers acquire information, the expected net present value from the optimal project choice decision less the cost of information acquisition is

$$
\begin{aligned}
& \int_{s^{*}}^{s_{2}} f(s)\left[p(s) \pi_{g}+(1-p(s)) \pi_{b}-K\right] d s-c \\
& =\gamma\left[1-F\left(s^{*} \mid G\right)\right] \pi_{g}+(1-\gamma)\left[1-F\left(s^{*} \mid B\right)\right] \pi_{b}-K\left[1-F\left(s^{*}\right)\right]-c .
\end{aligned}
$$

Thus an optimal project choice decision with information acquisition leads to the revision of success probability from $\gamma$ to $\frac{\gamma\left[1-F\left(s^{*} \mid G\right)\right]}{1-F\left(s^{*}\right)}$ which is larger than $\gamma$ since $F\left(s^{*}\right)>F\left(s^{*} \mid G\right)$ due to the assumption that $F(\cdot \mid G)$ stochastically dominates $F(\cdot \mid B)$. We assume that the net present value in (1) is positive. Replacing $K$ with $\gamma \pi_{g}+(1-\gamma) \pi_{b}$ and simplifying, this assumption can be stated as

Assumption 2: $\gamma\left[F\left(s^{*}\right)-F\left(s^{*} \mid G\right)\right] \pi_{g}+(1-\gamma)\left[F\left(s^{*}\right)-F\left(s^{*} \mid B\right)\right] \pi_{b}>c$.

The (LHS) of the above inequality will be called the value of information, denoted by $\mathcal{V}$. Assumption 2 implies that information is valuable in the first-best world where the optimal project choice decision described above can be implemented. The first-best optimum in this model thus consists of information acquisition and the above optimal project choice decision. Our primary goal is to see whether a contract that the owner will offer the manager can implement the first-best optimum when the manager's type is private information.

The time line and the information structure for the model are as follows. At date 0, the owner randomly selects a manager to offer a contract. At date 1 , the chosen manager decides whether or not to learn his type at private cost of $c$. At date 2, the manager makes the project choice decision. ${ }^{(10)}$ If the manager decides to abort the project, then he

(10) Insofar as the manager is the only party who can observe the signal, it does not matter whether the 
is fired at some severance payment according to the initial contract. If the manager decides to undertake the project, then the remaining terms of initial contract are executed at date 3. Throughout the paper, we assume that the project choice decision $(d=1$ if chosen, and $d=0$ otherwise) is observable and verifiable, hence can be contracted upon. The return from the project $\left(r=\pi_{g}\right.$ or $\left.r=\pi_{b}\right)$ is also assumed observable and verifiable in section 4 where return-based contracts are studied. In section 5, we assume that return is observable but not verifiable, hence cannot be contracted upon. The main reason for this is to justify the use of non-return-based contracts. All other aspects of the model (the manager's decision of information acquisition and the signals observed) are private information and cannot be contracted upon.

\section{Optimal Contract When Return is Verifiable}

Contracts in this section specify compensation to the manager based on the project choice decision and the return from the project. Thus a return-based contract can be denoted by a triple $\left(t_{1}, t_{2}, t_{3}\right)$ where $t_{1}$ is the payment if $d=1, r=\pi_{g}, t_{2}$ is if $d=1, r=\pi_{b}$ and $t_{3}$ is if $d=0$. We will focus on contracts that satisfy limited liability (LL), individual rationality for both agents ((IR-O) for the owner and (IR-M) for the manager), and incentive compatibility (IC). (11) Before we spell out these constraints, notice that any project choice decision that will be made by the manager follows a cutoff rule. Suppose the manager chose the project given a signal $s^{\prime}$. Expected compensation from this decision must not be smaller than that from aborting the project, or $p\left(s^{\prime}\right) t_{1}+\left(1-p\left(s^{\prime}\right)\right) t_{2} \geq t_{3}$. Since $p^{\prime}(s)>0$ by Lemma 1 , any decision rule should thus include an interval $\left[s^{\prime}, s_{2}\right]$ as the range of signal values at which the project must be undertaken. A project choice decision for which the project is undertaken for the range of signal values $\left[s, s_{2}\right]$ will be simply denoted by $[s]$.

owner makes the project choice decision based on the report made by the manager (i.e., the owner has formal authority and the manager has real authority in the language of Aghion and Tirole (1997)), or the manager makes the decision (i.e., the manager has both formal and real authority).

(11) Consider a general mechanism where the owner asks the manager to make a report regarding the observed signal based on which the owner makes the project choice decision. By the revelation principle, one can restrict attention to a direct mechanism and truth-telling by the manager if he observed a signal. The conditions guaranteeing that the manager gathers information and truthfully reports the observed signals can be stated as incentive compatibility. A slight variation of the argument in Choe (1998) can be used to show that the revelation principle holds in the current setup. 
Suppose now the owner wants to implement a project choice decision $\left[s^{\prime}\right]$. Denoting ex ante expected payoffs for the owner and the manager by $V_{0}\left(s^{\prime}\right)$ and $U_{0}\left(s^{\prime}\right)$ respectively, we have the following limited liability and individual rationality constraints.

(LL) $0 \leq t_{i}, i=1,2,3$.

$(\mathrm{IR}-\mathrm{O}) \quad V_{0}\left(s^{\prime}\right) \equiv \int_{s^{\prime}}^{s_{2}} f(s)\left[p(s)\left(\pi_{g}-t_{1}\right)+(1-p(s))\left(\pi_{b}-t_{2}\right)-K\right] d s+\int_{s_{1}}^{s^{\prime}} f(s)\left(-t_{3}\right) d s \geq 0$.

$(\mathrm{IR}-\mathrm{M}) \quad U_{0}\left(s^{\prime}\right) \equiv \int_{s^{\prime}}^{s_{2}} f(s)\left[p(s) t_{1}+(1-p(s)) t_{2}\right] d s+\int_{s_{1}}^{s^{\prime}} t_{3} f(s) d s-c \geq 0$.

For incentive compatibility, we need conditions that lead the manager to choose the decision $\left[s^{\prime}\right]$ over the following alternatives: (i) always undertake the project without information acquisition; (ii) always abort the project without information acquisition; (iii) acquire information and make a project choice decision other than $\left[s^{\prime}\right]$; (iv) randomize between (i) and (ii). As the alternative (iv) is dominated by either (i) or (ii), we need to consider only the first three, which are formally stated below.

$$
\begin{aligned}
& \text { (IC-i) } U_{0}\left(s^{\prime}\right) \geq \gamma t_{1}+(1-\gamma) t_{2} . \\
& \text { (IC-ii) } U_{0}\left(s^{\prime}\right) \geq t_{3} . \\
& \text { (IC-iii) } U_{0}\left(s^{\prime}\right) \geq \int_{s}^{s_{2}} f(x)\left[p(x) t_{1}+(1-p(x)) t_{2}\right] d x+\int_{s_{1}}^{s} t_{3} f(x) d x-c \text { for all } s .
\end{aligned}
$$

An optimal contract can be identified in two steps. First, for each project choice decision $\left[s^{\prime}\right]$, the owner's problem is to select a contract $\left(t_{1}, t_{2}, t_{3}\right)$ to maximize her expected payoff subject to the above constraints. Once such a contract is identified for each project choice decision, then the next step is to find a project choice decision that will maximize the owner's expected payoff. Thus the owner's problem is

$\operatorname{Maximize}_{\left(s^{\prime}, t_{i} \geq 0, i=1,2,3\right)} V_{0}\left(s^{\prime}\right)$ subject to (IR-0), (IR-M), (IC-i), (IC-ii), (IC-iii) $\forall s^{\prime}$. (2)

The following proposition shows that an optimal contract implements the first-best optimal project choice decision. 
Proposition 1: At the solution to problem (2), the project choice decision is the first-best one, $\left[s^{*}\right]$.

Restricting attention to the project choice decision $\left[s^{*}\right]$, we now simplify (IC-iii) for the decision $\left[s^{*}\right]$. It is equivalent to $s^{*}$ being a global maximizer of $\int_{s}^{s_{2}} f(x)\left[p(x) t_{1}+(1-\right.$ $\left.p(x)) t_{2}\right] d x+\int_{s_{1}}^{s} t_{3} f(x) d x-c$. Due to assumption 1, this constraint can be replaced by the first-order condition for the corresponding optimization problem.

Lemma 2: Suppose (IC-i) and (IC-ii) are satisfied for $\left[s^{*}\right]$. Then (IC-iii) is equivalent to $t_{3}=\gamma t_{1}+(1-\gamma) t_{2}$ and $t_{1}>t_{2}$.

That $t_{3}=\gamma t_{1}+(1-\gamma) t_{2}$ and $t_{1}>t_{2}$ are necessary and sufficient for (IC-iii) is reminiscent of incentive compatibility constraints in adverse selection literature. ${ }^{(12)}$ While the conditions in Lemma 2 guarantee ex ante incentive compatibility, they also imply that interim incentive compatibility is satisfied for each type of manager. That is, once the signal is observed, the manager of type $s<s^{*}$ does not have incentives to undertake the project. Otherwise, expected compensation is $p(s) t_{1}+(1-p(s)) t_{2}<\gamma t_{1}+(1-\gamma) t_{2}=t_{3}$, falling short of the compensation from aborting the project. Similarly, the manager of type $s \geq s^{*}$ does not have incentives to abort the project.

Substituting $t_{3}=\gamma t_{1}+(1-\gamma) t_{2}$ into the expected payoffs for the manager and the owner, and arranging terms yields

$$
\begin{gathered}
U_{0}=t_{1} \gamma\left[1-F\left(s^{*} \mid G\right)+F\left(s^{*}\right)\right]+t_{2}(1-\gamma)\left[1-F\left(s^{*} \mid B\right)+F\left(s^{*}\right)\right]-c, \\
V_{0}=\mathcal{V}-c-U_{0}
\end{gathered}
$$

where $\mathcal{V}$ was defined as the value of information. Also, given $t_{3}=\gamma t_{1}+(1-\gamma) t_{2}$, (IC-i) and (IC-ii) are equivalent. Since the owner's problem is equivalent to minimizing the expected

(12) Given $t_{3}=\gamma t_{1}+(1-\gamma) t_{2}$ and $t_{1}>t_{2}$, the manager's expected compensation is increasing in observed signals if the manager follows the optimal project choice decision. Note the analogy with adverse selection literature where weak monotonicity of allocation in private types is necessary and sufficient for incentive compatibility under the single-crossing property. 
payment to the manager, (IC-i) will be binding at the solution to problem (2), or $t_{1} \gamma\left[F\left(s^{*}\right)-\right.$ $\left.F\left(s^{*} \mid G\right)\right]+t_{2}(1-\gamma)\left[F\left(s^{*}\right)-F\left(s^{*} \mid B\right)\right]-c=0 . \quad$ Note also that (IR-M) is satisfied whenever (IC-i) or (IC-ii) are since (LL) precludes negative compensation to the manager. Ignoring (IR-O) for a moment, the owner's problem in (2) is then to choose nonnegative values for $\left(t_{1}, t_{2}\right)$ to minimize the expected compensation to the manager given in (3) subject to binding (IC-i) and $t_{1}>t_{2}$. Once the solution to this problem is identified, $t_{3}$ can be calculated as $\gamma t_{1}+(1-\gamma) t_{2}$.

It is easy to see that, at the solution to the above problem, limited liability for $t_{2}$ is binding, i.e., $t_{2}=0$. The intuition is simple. As the manager is risk neutral and $\pi_{b}$ is a sign of bad performance which is more likely to be observed if the manager made suboptimal project choice decisions, incentives for optimal project choice can be best provided by making the difference between $t_{1}$ and $t_{2}$ as large as possible. This, along with (IC-iii) and binding (IC-i), leads to $t_{1}=\frac{c}{\gamma\left[F\left(s^{*}\right)-F\left(s^{*} \mid G\right)\right]}, \quad t_{2}=0$, and $t_{3}=\frac{c}{F\left(s^{*}\right)-F\left(s^{*} \mid G\right)}$. This contract satisfies (LL) since the stochastic dominance condition implies $F\left(s^{*}\right)>F\left(s^{*} \mid G\right)$.

One last thing to check is if the above contract satisfies (IR-O). Substituting the above contract to $V_{0}$ and setting $V_{0} \geq 0$ leads to the inequality $c \leq\left(\frac{F\left(s^{*}\right)-F\left(s^{*} \mid G\right)}{1-F\left(s^{*} \mid G\right)+F\left(s^{*}\right)}\right) \mathcal{V}$. Note that assumption 2 is not enough to guarantee this inequality. What assumption 2 means is that information is valuable in the first-best world where the owner need not incur incentive costs to implement an optimum. In the second-best world where providing incentives to the manager is costly, the cost of information acquisition $c$ should not be too large for (IR-O) to be satisfied. The cost of providing such incentives to the manager increases as the private cost of information acquisition increases. For the set of contracts satisfying all the constraints to be nonempty, we thus need an upper bound on $c$ smaller than the value of information.

Proposition 2: Suppose $c \leq\left(\frac{F\left(s^{*}\right)-F\left(s^{*} \mid G\right)}{1-F\left(s^{*} \mid G\right)+F\left(s^{*}\right)}\right) \mathcal{V}$ so that the set of contracts satisfying the constraints is not empty. Then an optimal contract is given by $t_{1}=\frac{c}{\gamma\left[F\left(s^{*}\right)-F\left(s^{*} \mid G\right)\right]}, t_{2}=$ $0, \quad t_{3}=\frac{c}{F\left(s^{*}\right)-F\left(s^{*} \mid G\right)}$.

At an optimal contract, the value of information less the cost of information acquisition is shared between the owner and the manager: $V_{0}=\mathcal{V}-\frac{c}{F\left(s^{*}\right)-F\left(s^{*} \mid G\right)}-c, U_{0}=\frac{c}{F\left(s^{*}\right)-F\left(s^{*} \mid G\right)}$. In particular, the manager enjoys strictly positive information rent. The main reason for this is 
limited liability, without which the owner can extract the entire rent by setting $t_{2}$ a negative number such that $\gamma t_{1}+(1-\gamma) t_{2}=t_{3}=0$. Such a contract will satisfy all the incentive constraints and make (IR-M) binding.

Given the model scenario described before, the contract in Proposition 2 can be interpreted as a compensation package consisting of a base salary corresponding to $t_{2}$, a golden parachute represented by $t_{3}$, and a bonus given by $t_{1}-t_{2}$. That the base salary is $t_{2}=0$ is due to risk neutrality and limited liability. For risk-averse managers, the base salary would be generally positive. The interpretation of $t_{3}$ as a golden parachute is justified by the fact that it is essentially payment for leaving managers whether the departure has been initiated by hostile takeover or by the existing board. Its main rationale is to give managers incentives not to distort the running of the firm, or the investment decision in the current context, for fear of replacement by (potentially) better managers.

Proposition 2 leads to a couple of observations: (i) the bonus, golden parachute, and the manager's ex ante expected payoffs are all increasing in the cost of information acquisition; (ii) the bonus and golden parachute are positively related. If the cost of information acquisition is positively related to the size of the firm, then the first observation reconfirms the positive relation between the size of the firm and executive pay. ${ }^{(13)}$ The second point simply states that the golden parachute has to reflect the opportunity cost of leaving the firm.

Increasing size of managerial compensation is largely due to stock options or stocks held by managers (Hall, 1998; Hall and Liebman, 1998). To have a richer theory of optimal managerial contract, it thus seems imperative to have a model that could explain the use of these instruments. One obvious rationale for using stocks and stock options to motivate managers is that contracts need not be explicitly based on performance signals. For example, as possible explanations for a small pay-performance sensitivity of managerial compensation, Jensen and Murphy (1990a) contend that performance signals such as accounting earnings can be manipulated while stock prices may be too noisy a signal for manager's effort. The possibility of earnings manipulation by managers seems to have support by many empirical studies in accounting as well. In the next section, we make an extreme assumption that the return from the project is not verifiable, hence cannot be contracted upon. While this assumption needs

(13) Baker et al. (1988) report that the best documented empirical regularity in this regard is an elasticity of compensation with respect to firm sales of about 0.3 . 
justification, we leave it to readers to resort either to Jensen and Murphy's explanations, or to the rationale given in incomplete contracting literature. ${ }^{(14)}$

\section{Optimal Contract When Return Is Not Verifiable}

When the return from the project is not verifiable, contracts can specify compensation to the manager based only on whether or not the project is undertaken. Nonetheless, the owner can make compensation indirectly dependent on return since the project choice decision at date 2 was assumed publicly observable. The observation of project choice leads the market to revise its belief about the manager's type, based on which the value of the firm is determined at date 2. We assume that the market is rational: the value of the firm is determined based on the project choice decision expected by the market, which is confirmed at the equilibrium. Thus an equilibrium consists of a managerial contract, a project choice decision, and the market's valuation rule such that, given the valuation rule, the managerial contract and the project choice decision are optimal for the owner, and the valuation rule is consistent with the project choice decision.

This section starts by showing that the owner cannot implement the first-best optimum with contracts that do not rely on the market's valuation. We will call these simple contracts. Next we show that this inefficiency can be overcome by using contracts that make the manager's compensation dependent on the market's valuation. For this, we consider two types of contracts: contracts with stock ownership for which managerial share trading is restricted to date 3 , and contracts with stock options.

\subsection{Inefficiency of A Simple Contract}

If the return from the project is not verifiable, a contract can be represented by a triple $\left(B_{0}, P, S\right)$ where $B_{0}$ is fixed base salary, $P$ is the payment when the project is aborted,

(14) There are at least two ways incomplete contracting literature justifies the use of incomplete contracts. The first simply assumes intrinsic incompleteness in contracting technologies either due to bounded rationality or due to transactions costs (for example, Williamson, 1985; Hart, 1995). The second approach endogenizes incomplete contracts based on strategic ambiguity that, if some aspects of environment cannot be written into contracts, then there may be gains in leaving some other aspects out of contracts as well (Bernheim and Whinston, 1998). See also Maskin and Tirole (1999), and Hart and Moore (1999) in the special issue of the Review of Economic Studies on contracts. 
or a golden parachute, and $S$ is the payment when the project is undertaken. Regardless of this change in contracting environment, the first-best optimum still consists of information acquisition by the manager and the optimal decision $\left[s^{*}\right]$.

We start this section by showing that a 'simple' contract cannot implement the first-best optimum. By a simple contract, we mean a contract for which $P$ and $S$ also represent a fixed payment. Limited liability imposes nonnegativity constraints on all these components. For a simple contract to implement the first-best optimum, we would need the manager to learn his type and follow the optimal project choice rule instead of (i) not learning his type and always aborting the project, (ii) not learning his type and always undertaking the project, and (iii) learning his type but following a project choice rule different from the optimal one. ${ }^{(15)}$ The first two incentive compatibility constraints can be expressed as

$$
\begin{aligned}
& \text { (IC-i) } U_{0} \equiv P\left[1-F\left(s^{*} \mid B\right)\right]+S\left[1-F\left(s^{*} \mid G\right)\right]+B_{0}-c \geq B_{0}+S, \\
& \text { (IC-ii) } U_{0} \geq B_{0}+P .
\end{aligned}
$$

The third incentive compatibility constraints are now essentially interim incentive compatibility constraints. Since $P$ and $S$ are fixed, we need only consider two cases: the manager with type $s<s^{*}$ should not have incentives to undertake the project; the manager with type $s \geq s^{*}$ should not have incentives to abort the project. From these two, we obtain

$$
\text { (IC-iii) } P=S \text {. }
$$

It is immediate to see that (IC-iii) leads to the violation of (IC-i) and (IC-ii). Simply put, if managers receive the same payment regardless of project choice decisions (because of (IC-iii)), then they do not have incentives to learn their types at private cost. Since $P$ is paid if and only if the project is aborted with the current manager, the only remedy for this inefficiency would be to make the payment represented by $S$ dependent on subsequent return from the project. However, nonverifiability of return precludes the possibility of linking $S$ directly to return. Indirect ways to link $S$ to return are various arrangements whereby part of the right to return is transferred to the manager with whom the project is undertaken. In what follows, we will explore into these possibilities.

(15) Again there is no need to consider randomization over the options (i) and (ii). 


\subsection{Optimal Contract with Restricted Stock Ownership}

This section studies a contract $\left(B_{0}, P, S\right)$ where $B_{0}$ is a fixed base salary, ${ }^{(16)} P$ is a golden parachute, and $S$ represents a fraction of the value of the firm awarded to the manager with whom the project is undertaken, i.e., stock ownership. In accordance with usual practice, the stock ownership is subject to limited liability. We will consider cases where this ownership share can be traded either at date 2 or at date 3 .

If the ownership share can be traded at and after date 2 , what will be the market value of the firm? Consider first date 3 when the return from the project is realized and publicly observed. Out of this return, $B_{0}$ has to be paid to the manager, and $K$ has to be paid to the owner whenever possible. Since the ownership share represents residual claim, the value of the firm will be equal to the value of residual if it is nonnegative, and zero if it is negative. Date 3 value of the firm is thus $V_{3}(r) \equiv \max \left\{r-B_{0}-K, 0\right\}$ for $r=\pi_{g}, \pi_{b}$. Since $\pi_{b}<K$, the value of the firm is equal to zero in case of failure, and so we will simply denote the value of the firm in case of success as $V_{3}$. Moreover, at any contract satisfying the owner's individual rationality constraint, $V_{3}$ has to be positive, or $B_{0}<\pi_{g}-K$, since the owner receives positive payoff only when the return is $\pi_{g}$. Therefore we can write the value of the firm at date 3 as

$$
V_{3} \equiv \pi_{g}-B_{0}-K
$$

The value of the firm at date 2 can be recursively defined. Suppose the market expects the project choice decision $\left[s^{\prime}\right]$. At date 2, the announcement of project choice leads the market to update the probability of success. If the contract $\left(B_{0}, P, S\right)$ is incentive-compatible for the decision $\left[s^{\prime}\right]$, then the market correctly updates the probability of $s$ conditional on the announcement $d=1$ using Bayes' rule: $\operatorname{Pr}(s \mid d=1)=\frac{f(s)}{\int_{s^{\prime}}^{s_{2}} f(s) d s}=\frac{f(s)}{1-F\left(s^{\prime}\right)}$ if $s \geq s^{\prime}$, and $\operatorname{Pr}(s \mid d=1)=0$, otherwise. As the value of the firm at date 2 should be equal to the expected value of the firm at date 3 , the announcement of $d=1$ will lead to date 2 value of the firm equal to

(16) As there is no discounting, we assume, without loss of generality, that $B_{0}$ is paid at date 2 to departing managers, and at date 3 to managers with whom the project is undertaken. 


$$
V_{2}\left(s^{\prime}\right) \equiv \int_{s^{\prime}}^{s_{2}} \frac{f(s)}{1-F\left(s^{\prime}\right)} p(s) V_{3} d s=\frac{\gamma\left[1-F\left(s^{\prime} \mid G\right)\right]}{1-F\left(s^{\prime}\right)} V_{3}
$$

Finally, the initial value of the firm can be calculated. The announcement of $d=0$ at date 2 leads to the value of the firm equal to zero, while incentive-compatible contracts will imply the value of the firm equal to $V_{2}\left(s^{\prime}\right)$ upon the announcement of $d=1$ at date 2 . Again, incentive compatibility implies that the probability of $d=1$ is $1-F\left(s^{\prime}\right)$. Thus the initial value of the firm is

$$
V_{1}\left(s^{\prime}\right) \equiv\left[1-F\left(s^{\prime}\right)\right] V_{2}\left(s^{\prime}\right)=\gamma\left[1-F\left(s^{\prime} \mid G\right)\right] V_{3} .
$$

Consider first a case where there is no restriction on when to trade ownership share. Unless the size of golden parachute is sufficiently large, there is a possibility for managers with types $s<s^{*}$ to misrepresent their types to sell their ownership share at date 2 . This puts a lower bound on the size of golden parachute. On the other hand, the golden parachute cannot be too large. For otherwise, managers with types $s \geq s^{*}$ may have incentives to deliberately abort the project. As the next lemma shows, these two restrictions on the size of golden parachute lead to the inefficiency of contracts with unrestricted stock ownership.

Lemma 3: A contract $\left(B_{0}, P, S\right)$ where $S$ is the ownership share tradeable either at date 2 or at date 3 is not incentive compatible for the project choice decision $\left[s^{*}\right]$, hence cannot implement the first-best optimum.

As unrestricted stock ownership as in Lemma 3 cannot implement the first-best optimum, it seems natural to consider some form of restriction on when managers can trade their ownership share. Suppose the ownership share can be traded only at date 2. Intuitively, this should not improve on the simple contract examined in the previous subsection. If the ownership share can be traded only at date 2 and if the contract is to be incentive compatible for all types, then the expected compensation at date 2 has to be the same for all types of managers when they make project choice decisions based on their true types. This is precisely as in the case of a simple contract where the main reason for inefficiency is the inability of the owner to reward 
'better' managers more favorably. Thus a contract with stock ownership which is restricted to be traded before the realization of return cannot implement the first-best optimum.

Lemma 4: A contract $\left(B_{0}, P, S\right)$ where $S$ is the ownership share tradeable only at date 2 is not incentive compatible for the project choice decision $\left[s^{*}\right]$, hence cannot implement the first-best optimum.

What causes the inefficiency in Lemmas 3 and 4 ? Essentially it stems from stringent interim incentive compatibility constraints, mainly due to the incentives of managers with types $s<s^{*}$ to misrepresent their types for an immediate sale of their stock ownership at date 2. A logical remedy for this inefficiency would then be a restriction on managers' share trade at date 2. The final case to study is thus contracts for which ownership share can be traded only at date $3 .^{(17)}$ At date 3 , the return from the project is publicly observed and correctly reflected in the value of the firm, implying that 'better' managers will expect higher expected compensation at date 2. Indeed, a contract with stock ownership that is restricted to be traded only at date 3 can implement the first-best optimum. Moreover, an argument similar to what was used to prove Proposition 1 can be applied to show that an optimal contract implements the first-best optimum.

Proposition 3: An optimal contract with stock ownership is given by $\left(B_{0}, P, S\right)$ such that $\quad B_{0}=0, \quad P=\frac{c}{F\left(s^{*}\right)-F\left(s^{*} \mid G\right)}, \quad S=\frac{c}{\gamma\left(\pi_{g}-K\right)\left[F\left(s^{*}\right)-F\left(s^{*} \mid G\right)\right]} \quad$ where $\quad S$ represents the manager's stock ownership restricted to be traded only at date 3 .

The contract in Proposition 3 will be called a contract with restricted stock ownership, in contrast to the contract in section 3 , which will be called a bonus contract. Note that the size of golden parachute is the same under both contracts. As both contracts implement the first-best optimum, they are not Pareto-comparable. Indeed, it is easy to show that the sum of ex ante expected payoffs for the manager and the owner is equal to the value of information less the cost of information acquisition in both contracts. Then which contract should be preferred by the owner, or by the manager? One might wonder if the contract with restricted

(17) For a sample of 371 Fortune 500 firms in 1980, Kole (1997) reports that the average wait to vest executive stock awards was 28.7 months. 
stock ownership should be disadvantageous to the owner because of her inability to condition managerial compensation on return. However, this turns out not to be the case.

Proposition 4: The optimal bonus contract and the optimal contract with restricted stock ownership are strongly payoff-equivalent. That is, the distribution of managers' (owner's, resp.) ex post payoffs under the bonus contract is the same as the distribution of managers' (owner's, resp.) ex post payoffs under the contract with restricted stock ownership.

The proof of Proposition 4 is immediate upon comparing the two optimal contracts. First, straightforward algebra shows that the sum of ex ante expected payoffs for the manager and the owner under the contract with restricted stock ownership is equal to the net value of information: $\mathcal{V}-c$. This was also the case with the bonus contract. Second, the size of golden parachute is the same in both contracts. Finally, it is easy to see that the ex post value of manager's stock ownership given by $S V_{3}$ is equal to the ex post value of the manager's bonus given by $t_{2}$.

Proposition 4 points to an important direction in designing optimal managerial contract. For reasons to favor one form of contract over another, managers' risk aversion alone is not a good place to look at. As long as the owner knows the distribution of return, and as long as the set of incentive-compatible contracts is not empty, the owner can replicate exactly the same distribution of payoffs for managers using either bonus or restricted stock ownership. This can be done by setting $t_{1}=S V_{3}+B_{0}, t_{2}=B_{0}$, and $t_{3}=P+B_{0}$, leaving risk-averse managers indifferent between the two types of contracts. Of course, an optimal contract in this case will generally have $t_{2}=B_{0}>0$. However, managers' risk aversion combined with other elements such as the possibility of earnings manipulation or the information content of earnings could change the payoff-equivalence result. As discussed in the introduction, this has been a focus of numerous studies in accounting.

\subsection{Optimal Contract with Stock Options}

When return is not verifiable, yet another way of linking executive compensation to performance is using stock options, which is the focus of this section. Specifically, we study a 
contract $\left(B_{0}, P, \sigma, X\right)$ where $B_{0}$ and $P$ are the same as before, and $\sigma$ is the fraction of the value of the firm which the manager can buy either at date 2 or at date 3 at an exercise price given by $X$. In other words, $\sigma$ represents (American-type) call options on stocks awarded to the manager at date 0 . When one thinks of stock ownership equivalent to stock options with zero exercise price, the discussions in the previous section should make it clear that restricting the exercise of options to date 2 cannot be incentive compatible for the first-best project choice decision.

As the size of option grant $(\sigma)$ can be traded off against the exercise price $(X)$, one cannot in general derive a unique optimal contract with stock options. That is, the same incentives can be provided by different combinations of $(\sigma, X)$. When options can be exercised either at date 2 or at date 3 , however, incentive compatibility puts a lower bound on the exercise price. If the exercise price is too low, then managers may be tempted to undertake the project for an immediate exercise of options even when the project has negative expected return. On the other hand, the exercise price cannot be larger than the date 3 value of the project. Otherwise, options are always out of the money and so managers will not have incentives to gather information.

Lemma 5: A contract with stock options $\left(B_{0}, P, \sigma, X\right)$ is incentive compatible for the project choice decision $\left[s^{*}\right]$ if and only if $X_{l} \leq X \leq V_{3}$ and $P=\gamma \sigma\left(V_{3}-X\right) \geq \frac{c}{F\left(s^{*}\right)-F\left(s^{*} \mid G\right)}$ where $X_{l} \equiv \frac{V_{2}\left(s^{*}\right)-\gamma V_{3}}{1-\gamma}$.

The above lemma illustrates the nature of trade-off between the size of option grant and exercise price. Managers can choose either a risky project for possible increase in the value of their options, or a safer alternative. For an increase in the exercise price, the necessary upward adjustment in the size of option grant should thus reflect the opportunity cost of managers' risk taking. Other things equal, the factors that reduce the exercise date value of the firm without changing managers' incentives should require a downward adjustment in the exercise price. For example, if the firm has outstanding debt to be repaid at date 3, then the exercise price of managerial options should decrease in the amount of debt. ${ }^{(18)}$ This point can be used

(18) In this case, one can think of $V_{3}$ as the value of equity rather than the value of the firm. Garvey and Mawani (1999) provide empirical evidence for this. 
in characterizing the optimal contract with stock options. As is clear from the above lemma, the base salary reduces the date 3 value of the firm without having any incentive effect. A larger base salary will thus require a lower exercise price or a larger grant size, increasing the owner's costs of providing incentives to managers. It follows then that, at any optimal contract, the base salary should be set equal to zero. Also it can be shown that an optimal contract implements the first-best project choice decision.

Proposition 5: An optimal contract with stock options is given by $B_{0}=0, \quad P=$ $\frac{c}{F\left(s^{*}\right)-F\left(s^{*} \mid G\right)}, \quad \sigma=\frac{c}{\gamma\left(V_{3}-X\right)\left[F\left(s^{*}\right)-F\left(s^{*} \mid G\right)\right]}$, and $\frac{V_{2}\left(s^{*}\right)-\gamma V_{3}}{1-\gamma} \leq X \leq V_{3}$.

The contract with stock options (Proposition 5) differs from the contract with restricted stock ownership (Proposition 3) in that options can be exercised either at date 2 or at date 3 . This flexibility managers enjoy can be countered by the choice of exercise price by the owner. As shown in Lemma 5, a zero exercise price cannot be incentive compatible if options can be exercised at either date. Thus, for the contract with restricted stock ownership, managers' share trading needs to be restricted to date 3. Other than that, both types of contracts can provide exactly the same incentives. First, as both contracts implement the first-best optimum, they are not Pareto-comparable. In fact, it is a matter of simple calculation to show that the contract with stock options again leads to the sum of ex ante expected payoffs for the manager and the owner equal to the net value of information: $\mathcal{V}-c$. Second, note that the size of golden parachute is the same in both contracts. Moreover, it is easy to see that the ex post value of manager's stock ownership given by $S V_{3}$ is equal to the ex post value of manager's stock options given by $\sigma\left(V_{3}-X\right)$. This again establishes the payoff-equivalence of the two contractual forms.

Proposition 6: The optimal contract with stock options and the optimal contract with restricted stock ownership are strongly payoff-equivalent. That is, the distribution of managers' (owner's, resp.) ex post payoffs under the contract with stock options is the same as the distribution of managers' (owner's, resp.) ex post payoffs under the contract with restricted stock ownership. 


\section{Summary and Discussions}

This paper has studied an optimal contract for executives in two contracting environments. When contracts can be based on earnings, an optimal contract is shown to be a combination of base salary, golden parachute and bonus. If earnings are not verifiable, two types of optimal contracts were studied: a contract with restricted stock ownership, and a contract with stock options. Three main conclusions could be drawn. First, various components comprising a compensation package are interdependent. Second, the size of golden parachute is the same regardless of different contractual forms. Third and most importantly, these three types of optimal contracts are all payoff-equivalent in a strong sense: agents' ex ante and ex post payoffs are exactly the same under all three contracts.

Perhaps in retrospect, it may not be surprising that a highly simplified model as in this paper should lead to the payoff equivalence results. It thus seems imperative to have discussions on how the equivalence results are likely to change in a more realistic setting. At times, it has been discussed how the nature of contracts will change if there are possibilities of earnings manipulation by managers. The change, of course, will depend on the extent to which the information content of earnings report is reflected in stock prices. For example, if there is significant room for earnings manipulation and if markets do not take earnings information fully into account, then compensation based on stocks or stock options would be a better alternative than earnings-based bonus. The cost of using stock-based incentives is that of riskbearing by managers when they are risk averse. While we admit that earnings manipulation is not driven simply by managers' individual motives, such a possibility together with the information content of earnings report do seem to be an important element to take into account when asking the question about the relevance of contractual forms.

Other elements that need mentioning are managers' risk aversion, concern for reputation, private benefits of control, and the complexity of corporate hierarchy where good performance is often the result of consonant efforts by all those involved including the whim of nature. Risk aversion alone has been shown not to be a good explanation for the use of different forms of contracts since all three types of optimal contracts derived in this paper are payoff-equivalent in a strong sense. The next two do not seem to cause significant changes to the main conclusion 
of this paper. For example, suppose the manager enjoys some private benefits of control when the project is undertaken under his tenure, which leaving managers at date 2 will lose. Such private benefits of control increase the incentives of managers to stay in the office by making, if necessary, suboptimal decisions. All that is needed to defeat these incentives is to increase the size of severance payment. The simplest, albeit ad hoc, way of thinking about managers' concern for reputation would be similar to how private benefits of control are introduced leaving managers at date 2 incur private costs from loss of reputation. This again makes the departure more costly than otherwise, necessitating a larger severance payment. Neither of these are likely to change the other components of contracts. ${ }^{(19)}$

The complexity of corporate hierarchy does seem to be an important element that could bring about changes to the irrelevance result of this paper. Two of the most important roles executives of corporation are expected to play are setting directions - which was the main focus of this paper - and supervising employees on behalf of shareholders, the latter including the design of employment contracts for, and the monitoring of employees. The more complex corporate hierarchy becomes, the more onerous it is to perform the second role, and the more difficult it gets to predict performance. Again, risk aversion may then be an important factor to consider, which may call for the need to protect executives from risk and to motivate them to specialize in the role of direction setting while delegating supervisory role down the corporate hierarchy. In this case, compensation based on stock options could be a more attractive alternative than that based on stocks or earnings information. ${ }^{(20)}$

\section{Appendix}

Proof of Lemma 1: (a) follows directly from the monotone likelihood ratio condition. For (b), note first that there is an $s \in\left(s_{1}, s_{2}\right)$ such that $f(s \mid G)=f(s \mid B)$ since $f(s \mid G)$ and

(19) For example, consider a modification to the model in section 2 that the manager under whom the project is undertaken enjoys some private benefits equal to $\phi$. It can be shown that, at an optimal contract, only $t_{3}$ (as well as $P$ ) changes to $\phi+\frac{c}{F\left(s^{*}\right)-F\left(s^{*} \mid G\right)}$. Therefore the equivalence results of the paper remain intact.

(20) some also attribute the increasing use of stock options in the US to a favorable tax and accounting treatment of these instruments (Murphy, 1999). Empirical evidence is mixed. Yermack (1995), and Hall and Liebman (2000) find that the effect of tax and accounting considerations on the use of executive stock options is not significant in the US, while Klassen and Mawani (1999) report a positive correlation between the two in Canada. 
$f(s \mid B)$ are density functions. The monotone likelihood ratio condition guarantees that such an $s$ is unique, which is denoted by $s^{*}$. It then follows that $f\left(s^{*}\right)=\gamma f\left(s^{*} \mid G\right)+(1-\gamma) f\left(s^{*} \mid B\right)=$ $f\left(s^{*} \mid G\right)$, hence $p\left(s^{*}\right)=\gamma$.

Proof of Proposition 1: Suppose the owner wants to implement the project choice decision $\left[s^{\prime}\right]$. Then the manager's ex ante expected payoff from following this decision with information gathering is

$$
U_{0}\left(s^{\prime}\right) \equiv \gamma\left[1-F\left(s^{\prime} \mid G\right)\right] t_{1}+(1-\gamma)\left[1-F\left(s^{\prime} \mid B\right)\right] t_{2}+F\left(s^{\prime}\right) t_{3}-c .
$$

The first-order condition for (IC-iii) for the decision $\left[s^{\prime}\right]$ is given by $\frac{\partial U_{0}\left(s^{\prime}\right)}{\partial s}=0$ which leads to $t_{3}=\frac{\gamma f\left(s^{\prime} \mid G\right)}{f\left(s^{\prime}\right)} t_{1}+\frac{(1-\gamma) f\left(s^{\prime} \mid B\right)}{f\left(s^{\prime}\right)} t_{2}$. That is, $t_{3}$ is a weighted average of $t_{1}$ and $t_{2}$ when (IC-iii) is satisfied. Moreover, from the owner's problem of maximizing $V_{0}\left(s^{\prime}\right)$ subject to all the constraints, we have $t_{2}=0$ at the solution. Given this, the first-order condition becomes $t_{3}=\frac{\gamma f\left(s^{\prime} \mid G\right)}{f\left(s^{\prime}\right)} t_{1}$. Then the second-order condition for (IC-iii) is also satisfied since $\frac{\partial^{2} U_{0}\left(s^{\prime}\right)}{\partial s^{2}}=\gamma t_{1}\left\{\frac{f^{\prime}\left(s^{\prime}\right) f\left(s^{\prime} \mid G\right)}{f\left(s^{\prime}\right)}-f^{\prime}\left(s^{\prime} \mid G\right)\right\}<0$ due to the monotone likelihood ratio condition. For $t_{3}=\frac{\gamma f\left(s^{\prime} \mid G\right)}{f\left(s^{\prime}\right)} t_{1}>0$, remaining conditions to check are (IC-I): $U_{0}\left(s^{\prime}\right) \geq \gamma t_{1}$, and (IC-ii): $U_{0}\left(s^{\prime}\right) \geq t_{3} \quad$ since (IR-M) is satisfied whenever incentive compatibility constraints are. These conditions can be checked in two cases.

Suppose first $s^{\prime} \geq s^{*}$. Then $t_{3}=\frac{\gamma f\left(s^{\prime} \mid G\right)}{f\left(s^{\prime}\right)} t_{1} \geq \gamma t_{1}$ since the monotone likelihood condition implies that $\frac{f\left(s^{\prime} \mid G\right)}{f\left(s^{\prime}\right)}$ is increasing in $s^{\prime}$ and $\frac{f\left(s^{*} \mid G\right)}{f\left(s^{*}\right)}=1$. Thus if (IC-ii) is satisfied, then so will be (IC-i). In view of the owner's optimization problem, it is clear that (IC-ii) will be binding at the solution, leading us to $t_{1}=\frac{c f\left(s^{\prime}\right)}{\gamma f\left(s^{\prime}\right)\left[1-F\left(s^{\prime} \mid G\right)\right]-\gamma f\left(s^{\prime} \mid G\right)\left[1-F\left(s^{\prime}\right)\right]}$. Then the manager's ex ante expected payoff is given by $U_{0}\left(s^{\prime}\right)=t_{3}=\frac{c f\left(s^{\prime} \mid G\right)}{f\left(s^{\prime}\right)\left[1-F\left(s^{\prime} \mid G\right)\right]-f\left(s^{\prime} \mid G\right)\left[1-F\left(s^{\prime}\right)\right]}$. A simple calculation shows that the owner's ex ante expected payoff is $V_{0}\left(s^{\prime}\right)=\mathcal{V}\left(s^{\prime}\right)-c-U_{0}\left(s^{\prime}\right)$ where $\mathcal{V}\left(s^{\prime}\right)$ is the value of information for the project choice decision $\left[s^{\prime}\right]$. Noting that $\left[s^{*}\right]$ is the first-best decision, it is easy to see that $\mathcal{V}\left(s^{\prime}\right)$ is maximized when $s^{\prime}=s^{*}$. Moreover, differentiating $U_{0}\left(s^{\prime}\right)$ with respect to $s^{\prime}$ and using the monotone likelihood ratio condition, one can show that $U_{0}\left(s^{\prime}\right)$ is increasing in $s^{\prime}$ for $s^{\prime} \geq s^{*}$. Thus, for all $s^{\prime} \geq s^{*}, V_{0}\left(s^{\prime}\right)$ is maximized when $s^{\prime}=s^{*}$. 
Suppose now $s^{\prime}<s^{*}$. Then $t_{3}<\gamma t_{1}$ and only (IC-i) will be binding at the solution to the owner's problem. This leads us to $t_{1}=\frac{c f\left(s^{\prime}\right)}{\gamma f\left(s^{\prime} \mid G\right) F\left(s^{\prime}\right)-\gamma f\left(s^{\prime}\right) F\left(s^{\prime} \mid G\right)}$ and $U_{0}\left(s^{\prime}\right)=\gamma t_{1}$. The owner's ex ante expected payoff is again $V_{0}\left(s^{\prime}\right)=\mathcal{V}\left(s^{\prime}\right)-c-U_{0}\left(s^{\prime}\right)$ and the monotone likelihood ratio condition shows that $U_{0}\left(s^{\prime}\right)$ is decreasing in $s^{\prime}$ for all $s^{\prime}<s^{*}$. Thus, for all $s^{\prime}<s^{*}, \quad V_{0}\left(s^{\prime}\right)$ is maximized when $s^{\prime}=s^{*}$.

Proof of Lemma 2: The first-order necessary condition for $s^{*}$ being the global maximizer of $U(s) \equiv \int_{s}^{s_{2}} f(x)\left[p(x) t_{1}+(1-p(x)) t_{2}\right] d x+\int_{s_{1}}^{s} t_{3} f(x) d x-c$ is $U^{\prime}\left(s^{*}\right)=-t_{1} \gamma f\left(s^{*} \mid G\right)-t_{2}(1-\gamma)$ $f\left(s^{*} \mid B\right)+t_{3} f\left(s^{*}\right)=0$, or $t_{3}=\frac{\gamma f\left(s^{*} \mid G\right)}{f\left(s^{*}\right)} t_{1}+\frac{(1-\gamma) f\left(s^{*} \mid B\right)}{f\left(s^{*}\right)} t_{2}=\gamma t_{1}+(1-\gamma) t_{2} \quad$ where the second equality follows from $f\left(s^{*}\right)=f\left(s^{*} \mid G\right)=f\left(s^{*} \mid B\right)$. Given $t_{3}=\gamma t_{1}+(1-\gamma) t_{2}$, the second derivative of the objective function becomes

$$
\begin{aligned}
U^{\prime \prime}(s) & =-t_{1} \gamma f^{\prime}(s \mid G)-t_{2}(1-\gamma) f^{\prime}(s \mid B)+t_{3} f^{\prime}(s) \\
& =-t_{1} \gamma f^{\prime}(s \mid G)-t_{2}(1-\gamma) f^{\prime}(s \mid B)+\left[\gamma t_{1}+(1-\gamma) t_{2}\right] f^{\prime}(s) \\
& =\gamma t_{1}\left[f^{\prime}(s)-f^{\prime}(s \mid G)\right]+(1-\gamma) t_{2}\left[f^{\prime}(s)-f^{\prime}(s \mid B)\right] \\
& =\gamma(1-\gamma)\left(t_{1}-t_{2}\right)\left[f^{\prime}(s \mid B)-f^{\prime}(s \mid G)\right] .
\end{aligned}
$$

The monotone likelihood ratio condition is equivalent to $\frac{f^{\prime}(s \mid G)}{f(s \mid G)}>\frac{f^{\prime}(s \mid B)}{f(s \mid B)}$ for all $s$, which implies $f^{\prime}\left(s^{*} \mid G\right)>f^{\prime}\left(s^{*} \mid B\right)$ since $f\left(s^{*} \mid G\right)=f\left(s^{*} \mid B\right)$ by the definition of $s^{*}$. Thus $t_{1}>t_{2}$ guarantees the second-order sufficient condition for $s^{*}$ being a local maximizer of $U(s)$, or $U^{\prime \prime}\left(s^{*}\right)<0$. To prove that $s^{*}$ is the global maximizer of $U(s)$, it remains to show $U\left(s^{*}\right)=U_{0} \geq \max \left\{U\left(s_{1}\right), U\left(s_{2}\right)\right\}$. But $U\left(s_{1}\right)=\gamma t_{1}+(1-\gamma) t_{2}-c$ and $U\left(s_{2}\right)=t_{3}-c$. Therefore, given (IC-i) and (IC-ii), we must have $U\left(s^{*}\right)=U_{0} \geq \max \left\{U\left(s_{1}\right), U\left(s_{2}\right)\right\}$.

Proof of Lemma 3: The proof is by contradiction. Suppose $\left(B_{0}, P, S\right)$ implements the first-best optimum, hence incentive compatible for the decision $\left[s^{*}\right]$. Then the value of the firm evolves to $V_{2}\left(s^{*}\right)$ and $V_{3}$. Consider interim incentive compatibility constraints. Managers with types $s<s^{*}$ face three options: abort the project and receive $P+B_{0}$; undertake the project and trade their shares at date 2, receiving $S V_{2}\left(s^{*}\right)+B_{0}$; undertake the project and trade their shares at date 3 , receiving $S p(s) V_{3}+B_{0}$. Note that selling a fraction of $S$ at date 2 and the rest at date 3 is dominated by either of the second or third options. Thus interim incentive compatibility for managers with types $s<s^{*}$ can be written as 


$$
P+B_{0} \geq \sup \left\{S V_{2}\left(s^{*}\right)+B_{0}, S p(s) V_{3}+B_{0}: s<s^{*}\right\}=S V_{2}\left(s^{*}\right)+B_{0}
$$

where the second equality is from $V_{2}\left(s^{*}\right)=\left(\frac{1-F\left(s^{*} \mid G\right)}{1-F\left(s^{*}\right)}\right) \gamma V_{3}>\gamma V_{3}>p(s) V_{3}$ for all $s<s^{*}$. Therefore we have $P \geq S V_{2}\left(s^{*}\right)$.

Managers with types $s \geq s^{*}$ also face three options: abort the project and receive $P+B_{0}$; undertake the project and trade their shares at date 2, receiving $S V_{2}\left(s^{*}\right)+B_{0}$; undertake the project and trade their shares at date 3 , receiving $S p(s) V_{3}+B_{0}$. Again it is not necessary to consider a fractional share trade. Type $s \geq s^{*}$ managers will undertake the project as long as the expected payoff from selling stocks at either date is not smaller than $P+B_{0}$. As this has to be true for all $s \geq s^{*}$, interim incentive compatibility for managers with types $s \geq s^{*}$ can be written as

$$
P+B_{0} \leq \min \left\{\max \left\{S V_{2}\left(s^{*}\right)+B_{0}, S p(s) V_{3}+B_{0}\right\}: s \geq s^{*}\right\}=S V_{2}\left(s^{*}\right)+B_{0} .
$$

The two incentive compatibility constraints boil down to $P=S V_{2}\left(s^{*}\right)$. But then, as in simple contracts, managers do not have incentives to acquire information at private cost since the ex ante incentive compatibility constraint is violated.

Proof of Lemma 4: The proof is by contradiction. Suppose $\left(B_{0}, P, S\right)$ implements the first-best optimum, hence incentive compatible for $\left[s^{*}\right]$. If managers learn and make project choice decisions based on their true types, the ex ante expected payoff is given by $U_{0} \equiv S V_{2}\left(s^{*}\right)\left[1-F\left(s^{*}\right)\right]+P F\left(s^{*}\right)+B_{0}-c . \quad$ For ex ante incentive compatibility to be satisfied, $U_{0}$ should not be smaller than $P+B_{0}$, the expected payoff from always aborting the project without information acquisition, and $S V_{2}\left(s^{*}\right)+B_{0}$, the expected payoff from always undertaking the project without information acquisition. Consider now interim incentive compatibility: managers with type $s<s^{*}$ should not have incentives to undertake the project; managers with type $s \geq s^{*}$ should not have incentives to abort the project. It is easy to see that interim incentive compatibility boils down to $S V_{2}\left(s^{*}\right)+B_{0}=P+B_{0}$, which leads to the violation of the ex ante incentive compatibility constraint. 
Proof of Proposition 3: Suppose $\left(B_{0}, P, S\right)$ is a contract where $S$ represents the manager's stock ownership restricted to be traded only at date 3 . For this contract to implement the first-best optimum, it has to be incentive compatible for the decision $\left[s^{*}\right]$. If managers gather information and follow the optimal project choice decision based on their true types, then the ex ante expected payoff is given by

$$
\begin{aligned}
U_{0} & \equiv S \int_{s^{*}}^{s_{2}} f(s) p(s) V_{3} d s+P \int_{s_{1}}^{s^{*}} f(s) d s+B_{0}-c \\
& =S \gamma\left[1-F\left(s^{*} \mid G\right)\right] V_{3}+P F\left(s^{*}\right)+B_{0}-c .
\end{aligned}
$$

For the ex ante incentive compatibility to be satisfied, $U_{0}$ should not be smaller than $P+B_{0}$, the expected payoff from always aborting the project without information acquisition, and $S \gamma V_{3}+B_{0}$, the expected payoff from always undertaking the project without information acquisition.

Consider now interim incentive compatibility constraints: managers with type $s<s^{*}$ should not have incentives to undertake the project; managers with type $s \geq s^{*}$ should not have incentives to abort the project. The first leads to $P+B_{0} \geq S \gamma V_{3}+B_{0}$. The second interim incentive compatibility constraints are equivalent to $S p(s) V_{3}+B_{0} \geq P+B_{0}$ for all $s \geq s^{*}$. As the (LHS) of this inequality increases in $s$, it is sufficient to have the inequality hold when $s=s^{*}$, which leads to $S \gamma V_{3}+B_{0} \geq P+B_{0}$. Thus interim incentive compatibility boils down to $S \gamma V_{3}+B_{0}=P+B_{0}$, or $P=S \gamma V_{3}$. Substituting this into the ex ante incentive compatibility constraint and simplifying, we have $S \geq \frac{c}{\gamma V_{3}\left[F\left(s^{*}\right)-F\left(s^{*} \mid G\right)\right]}$.

We now turn to the owner's optimization problem. The owner provides $K$ for the project at date 2 if $d=1$, and pays $B_{0}+P$ to the manager if $d=0$. At date 3 , if the return is $\pi_{g}$, then the owner recovers $K$, pays $B_{0}$ to the manager, and receives the residual $(1-S) V_{3}$. If the return is $\pi_{b}$, then $K$ cannot be recovered, and so the owner receives $\pi_{b}$ and pays $B_{0}$ to the manager. Thus the owner's ex ante expected payoff at the first-best optimum can be written as

$$
\begin{aligned}
V_{0} & \equiv \int_{s^{*}}^{s_{2}} f(s)\left[p(s)(1-S) V_{3}+(1-p(s))\left(\pi_{b}-K\right)\right] d s-P \int_{s_{1}}^{s^{*}} f(s) d s-B_{0} \\
& =\gamma\left[1-F\left(s^{*} \mid G\right)\right](1-S) V_{3}+(1-\gamma)\left[1-F\left(s^{*} \mid B\right)\right]\left(\pi_{b}-K\right)-P F\left(s^{*}\right)-B_{0} .
\end{aligned}
$$


The owner's problem is then to choose $\left(B_{0} \geq 0, P \geq 0, S \in[0,1]\right)$ to maximize $V_{0}$ subject to $P=S \gamma V_{3}$ and $S \geq \frac{c}{\gamma V_{3}\left[F\left(s^{*}\right)-F\left(s^{*} \mid G\right)\right]}$. Substituting $P=S \gamma V_{3}$ into $V_{0}$ and differentiating with respect to $B_{0}$ leads to $-\gamma(1-S)\left[1-F\left(s^{*} \mid G\right)\right]-1$ which is negative for all $S \in[0,1]$. Thus $B_{0}=0$ and so $V_{3}=\pi_{g}-K$. The derivative of $V_{0}$ with respect to $S$ is also negative, implying that the constraint $S \geq \frac{c}{\gamma V_{3}\left[F\left(s^{*}\right)-F\left(s^{*} \mid G\right)\right]}$ has to be binding at the solution. Finally, $P$ is found by replacing $S=\frac{c}{\gamma\left(\pi_{g}-K\right)\left[F\left(s^{*}\right)-F\left(s^{*} \mid G\right)\right]}$ and $B_{0}=0$ into $P=S \gamma V_{3}$, leading to $P=\frac{c}{F\left(s^{*}\right)-F\left(s^{*} \mid G\right)}$.

Proof of Lemma 5: Consider first the interim incentive compatibility constraints. At date 2, managers with types $s<s^{*}$ face three alternatives: abort the project and receive $B_{0}+P$; choose the project and exercise options at date 2 , receiving $\sigma\left(V_{2}\left(s^{*}\right)-X\right)^{+}+B_{0}$; choose the project and wait until date 3 for the exercise of options, with expected payoff of $p(s) \sigma\left(V_{3}-X\right)^{+}+B_{0}$. Here $(\phi)^{+}$denotes the nonnegative part of $\phi$. Note that exercising a fraction of $\sigma$ at date 2 and the rest at date 3 is dominated by either of the second or third alternatives. Using Lemma 1, interim incentive compatibility constraints for managers with types $s<s^{*}$ can then be written as

$$
\begin{aligned}
P+B_{0} & \geq \sup \left\{\sigma\left(V_{2}\left(s^{*}\right)-X\right)^{+}+B_{0}, \quad p(s) \sigma\left(V_{3}-X\right)^{+}+B_{0}: s<s^{*}\right\} \\
& =\max \left\{\sigma\left(V_{2}\left(s^{*}\right)-X\right)^{+}+B_{0}, \quad \gamma \sigma\left(V_{3}-X\right)^{+}+B_{0}\right\} .
\end{aligned}
$$

Consider now managers with types $s \geq s^{*}$. They will correctly choose the project as long as the expected payoff from exercising options at either date is larger than that from aborting the project. As this has to be true for all $s \geq s^{*}$, interim incentive compatibility constraints become

$$
\begin{aligned}
P+B_{0} & \leq \min \left\{\max \left\{\sigma\left(V_{2}\left(s^{*}\right)-X\right)^{+}+B_{0}, \quad p(s) \sigma\left(V_{3}-X\right)^{+}+B_{0}\right\}: s \geq s^{*}\right\} \\
& =\max \left\{\sigma\left(V_{2}\left(s^{*}\right)-X\right)^{+}+B_{0}, \quad \gamma \sigma\left(V_{3}-X\right)^{+}+B_{0}\right\} .
\end{aligned}
$$

Thus interim incentive compatibility constraints can be satisfied for all types of managers if and only if $P=\max \left\{\sigma\left(V_{2}\left(s^{*}\right)-X\right)^{+}, \gamma \sigma\left(V_{3}-X\right)^{+}\right\}$. Define $X_{l} \equiv=\frac{V_{2}\left(s^{*}\right)-\gamma V_{3}}{1-\gamma}$. It is easy to see $X_{l} \leq V_{2}\left(s^{*}\right)$ and $X_{<}^{\gtrless} X_{l}$ if and only if $\gamma \sigma\left(V_{3}-X\right)^{+} \gtreqless \sigma\left(V_{2}\left(s^{*}\right)-X\right)^{+}$. 
Incentive compatibility can now be analyzed in several cases. Suppose first $X<X_{l}$. Then all options will be exercised at date 2 leading to the interim incentive compatibility, $P=\sigma\left(V_{2}\left(s^{*}\right)-X\right)$. Then managers' ex ante expected payoff from gathering information and implementing the optimal investment policy is $U_{0}=\int_{s^{*}}^{s_{2}} f(s) \sigma\left(V_{2}\left(s^{*}\right)-X\right) d s+$ $P \int_{s_{1}}^{s^{*}} f(s) d s+B_{0}-c=P+B_{0}-c$. But this is smaller than the payoff from always aborting the project without information gathering. Thus $X<X_{l}$ does not satisfy the ex ante incentive compatibility. Suppose next $X_{l} \leq X \leq V_{3}$. As $X_{l} \leq X$ implies $\gamma \sigma\left(V_{3}-X\right)^{+} \geq \sigma\left(V_{2}\left(s^{*}\right)-X\right)^{+}, \quad$ all options are exercise at date 3 leading to the interim incentive compatibility $P=\gamma \sigma\left(V_{3}-X\right)$. Given this, managers' ex ante expected payoff from gathering information and implementing the optimal investment policy becomes $U_{0}=\int_{s^{*}}^{s_{2}} f(s) p(s) \sigma\left(V_{3}-X\right) d s+P \int_{s_{1}}^{s^{*}} f(s) d s+B_{0}-c=\gamma \sigma\left(V_{3}-X\right)\left[1+F\left(s^{*}\right)-F\left(s^{*} \mid G\right)\right]+B_{0}-c$. To satisfy the ex ante incentive compatibility, $U_{0}$ should not be smaller than $P+B_{0}$, the payoff from always aborting the project without information gathering, and $\gamma \sigma\left(V_{3}-X\right)+B_{0}$, the expected payoff from always choosing the project without information gathering. But these two are the same if interim incentive compatibility is satisfied. Thus, for the ex ante incentive compatibility, we need $\gamma \sigma\left(V_{3}-X\right)\left[1+F\left(s^{*}\right)-F\left(s^{*} \mid G\right)\right]+B_{0}-c \geq \gamma \sigma\left(V_{3}-X\right)+B_{0}$ or $\sigma \geq \frac{c}{\gamma\left(V_{3}-X\right)\left[F\left(s^{*}\right)-F\left(s^{*} \mid G\right)\right]}$. Finally, if $X>V_{3}$ then options are always out of the money, and so managers do not have incentives to gather information.

Proof of Proposition 5: Consider the owner's optimization problem in implementing the decision $\left[s^{*}\right]$. The owner provides $K$ for the project at date 2 if $d=1$, and pays $B_{0}+P$ to the manager if $d=0$. In case of success at date 3 , the owner receives $\pi_{g}$, and pays $\sigma\left(V_{3}-X\right)+B_{0}$ to the manager as options will be exercised against her. If the return is $\pi_{b}$, then the owner receives $\pi_{b}$ and pays only $B_{0}$ to the manager as options will then be under water. Thus the owner's ex ante expected payoff at the first-best optimum can be written as

$$
\begin{aligned}
V_{0} & \equiv \int_{s^{*}}^{s_{2}} f(s)\left[p(s)\left(\pi_{g}-K-\sigma\left(V_{3}-X\right)\right)+(1-p(s))\left(\pi_{b}-K\right)\right] d s-P \int_{s_{1}}^{s^{*}} f(s) d s-B_{0} \\
& =\gamma\left[1-F\left(s^{*} \mid G\right)\right]\left[\pi_{g}-K-\sigma\left(V_{3}-X\right)\right]+(1-\gamma)\left[1-F\left(s^{*} \mid B\right)\right]\left(\pi_{b}-K\right)-P F\left(s^{*}\right)-B_{0} .
\end{aligned}
$$

Substituting $P$ into $V_{0}$ using Lemma 5, the owner's problem is to choose $\left(B_{0}, \sigma, X\right)$ to maximize $V_{0}$ subject to incentive compatibility. Differentiating $V_{0}$ with respect to 
$B_{0}$, we obtain $\quad \frac{\partial V_{0}}{\partial B_{0}}=\sigma\left[\gamma\left(1-F\left(s^{*} \mid G\right)\right)+F\left(s^{*}\right)\right]-1<0 \quad$ for all $\sigma \in[0,1]$ since $\gamma\left(1-F\left(s^{*} \mid G\right)\right)+F\left(s^{*}\right)<1$. Thus limited liability for $B_{0}$ has to be binding, or $B_{0}=0$. Next differentiating $V_{0}$ with respect to $\sigma$ for a given value of $X$ gives us $\frac{\partial V_{0}}{\partial \sigma}=-\gamma\left(V_{3}-\right.$ $X)\left[1-F\left(s^{*} \mid G\right)+F\left(s^{*}\right)\right]<0 . \quad$ Thus the incentive compatibility $\sigma \geq \frac{c}{\gamma\left(V_{3}-X\right)\left[F\left(s^{*}\right)-F\left(s^{*} \mid G\right)\right]}$ must be binding, leading us to $\sigma=\frac{c}{\gamma\left(V_{3}-X\right)\left[F\left(s^{*}\right)-F\left(s^{*} \mid G\right)\right]}$.

\section{References}

Aggarwal, R. K. and A. A. Samwick (1999), "The Other Side of the Trade-Off: The Impact of Risk on Executive Compensation", Journal of Political Economy, 107, No. 1, 65-105.

Aghion, P. and P. Bolton (1992), "An "Incomplete Contracts" Approach to Financial Contracting", Review of Economic Studies, 59, 473-494.

Aghion, P., Dewatripont, M. and P. Rey (1994), "Renegotiation Design with Unverifiable Information", Econometrica, 62, 257-282.

Aghion, P. and J. Tirole (1997), "Formal and Real Authority in Organizations", Journal of Political Economy, 105, No. 1, 1-29.

Agrawal, A. and C. R. Knoeber (1998), "Managerial Compensation and the Threat of Takeover", Journal of Financial Economics, 47, 219-239.

Baiman, S. and R. E. Verrecchia (1995), "Earnings and Price-Based Compensation Contracts in the Presence of Discretionary Trading and Incomplete Contracting", Journal of Accounting and Economics, 20, 93-121.

Baker, G., Jensen, M. and K. Murphy (1988), "Compensation and Incentives: Practice versus Theory", Journal of Finance, 43, No. 3, 593-616.

Bernheim, B. D. and M. D. Whinston (1998), "Incomplete Contracts and Strategic Ambiguity", American Economic Review, 88, No. 4, 902-932.

Bushman, R. M. and R. J. Indjejikian (1993), "Accounting Income, Stock Price and Managerial Compensation", Journal of Accounting and Economics, 16, 3-24.

Che, Y.-K. and D. B. Hausch (1999), "Cooperative Investments and the Value of Contracting", American Economic Review, 89, No. 1, 125-147. 
Choe, C. (1998), "A Mechanism Design Approach to an Optimal Contract under Ex Ante and Ex Post Private Information", Review of Economic Design, 3, No. 3, 237-255.

Chung, T.-Y. (1991), "Incomplete Contracts, Specific Investments, and Risk Sharing", Review of Economic Studies, 58, 1031-1042.

Cyert, R. M. and P. Kumar (1996), "Economizing by Firms through Learning and Adaptation", Journal of Economic Behavior and Organization, 29, 211-231.

Demski, J. S. and D. E. M. Sappington (1991), "Resolving Double Moral Hazard Problems with Buyout Agreements", RAND Journal of Economics, 22, 232-240.

Edlin, A. S. and B. E. Hermalin (1998), "Contract Renegotiation and Options in Agency Problems", mimeo. University of California.

Edlin, A. S. and S. Reichelstein (1996), "Holdups, Standard Breach Remedies, and Optimal Investment", American Economic Review, 86, No. 3, 478-501.

Garen, J. (1994), "Executive Compensation and Principal-Agent Theory", Journal of Political Economy, 102, No. 6, 1175-1199.

Garvey, G. T. and A. Mawani (1999), " Executive Stock Options as Home-Made Leverage: Why Financial Structure Does Not Affect Risk-Taking Incentives", mimeo., University of British Columbia.

Hadlock, C. J. and G. B. Lumer (1997), "Compensation, Turnover, and Top Management Incentives: Historical Evidence", Journal of Business, 70, No. 2, 153-187.

Hall, B. J. (1998), "The Pay to Performance Incentives of Executive Stock Options", mimeo., Harvard Business School.

Hall, B. J. and J. B. Liebman (1998), "Are CEOs Really Paid Like Bureaucrats?", Quarterly Journal of Economics, 113, No. 3, 653-691.

Hall, B. J. and J. B. Liebman (2000), "The Taxation of Executive Compensation", NBER Working Paper 7596.

Harris, E. G. (1990), “Antitakeover Measures, Golden Parachutes, and Target Firm Shareholder Wealth", RAND Journal of Economics, 21, No. 4, 614-625.

Hart, O. D. (1995), Firms, Contracts, and Financial Structure, Oxford: Oxford University Press.

Hart, O. D. and J. Moore (1988), "Incomplete Contracts and Renegotiation", Econometrica, 
56, $755-785$.

Hart, O. D. and J. Moore (1999), "Foundations of Incomplete Contracts", Review of Economic Studies, 66, 115-138.

Haubrich, J. G. (1994), "Risk Aversion, Performance Pay, and the Principal-Agent Problem", Journal of Political Economy, 102, 258-276.

Healy, P. (1985), "The Effect of Bonus Schemes on Accounting Decisions", Journal of Accounting and Economics, 7, 85-107.

Hermalin, B. E. and M. L. Katz (1993), "Judicial Modification of Contracts between Sophisticated Parties: A More Complete View of Incomplete Contracts and Their Breach", Journal of Law, Economics and Organization, 9, 230-255.

Holderness, C. G., Kroszner, R. S. and D. P. Sheehan (1999), "Were the Good Old Days That Good? Changes in Managerial Stock Ownership Since the Great Depression", Journal of Finance, 54, No. 2, 435-469.

Holmström, B. and P. Milgrom (1987), "Aggregation and Linearity in the Provision of Intertemporal Incentives", Econometrica, 55, 303-328.

Holmström, B. and J. Tirole (1993), "Market Liquidity and Performance Monitoring", Journal of Political Economy, 101, 678-709.

Jensen, M. and K. Murphy (1990a), "Performance and Top Management Incentives", Journal of Political Economy, 98, No. 2, 225-264.

Jensen, M. and K. Murphy (1990b), "CEO Incentives - It's Not How Much You Pay, But How", Harvard Business Review, No. 3, 138-153.

Kim, O. and Y. Suh (1993), "Incentive Efficiency of Compensation Based on Accounting and Market Performance", Journal of Accounting and Economics, 16, 25-54.

Klassen, K. and A. Mawani (1999), "The Impact of Financial and Tax Reporting Incentives on Option Grants to Canadian CEOs", mimeo., University of British Columbia.

Knoeber, C. R. (1986), "Golden Parachutes, Shark Repellents, and Hostile Tender Offers", American Economic Review, 76, 155-167.

Kole, S. R. (1997), "The Complexity of Compensation Contracts", Journal of Financial Economics, 43, 79-104.

Lambert, R. A. and D. F. Larcker (1985), "Golden Parachutes, Executive Decision-Making, 
and Shareholder Wealth", Journal of Accounting and Economics, 7, 179-203.

MacCleod, W. B. and J. M. Malcomson (1993), "Investments, Holdup, and the Form of Market Contracts", American Economic Review, 83, 811-837.

Maskin, E. and J. Tirole (1999), "Unforeseen Contingencies and Incomplete Contracts", Review of Economic Studies, 66, 83-114.

Milgrom, P. and J. Roberts (1992), Economics, Organization and Management, Englewood Cliffs: Prentice Hall.

Murphy, K. (1999), "Executive Compensation", in Ashenfelter, O. and D. Card (eds.), Handbook of Labor Economics, Vol. 3B, North-Holland.

Narayanan, M. P. and A. K. Sundaram (1998), "A Safe Landing? Golden Parachutes and Corporate Behavior", Working Paper 98015, University of Michigan Business School.

Nöldeke, G. and K. M. Schmidt (1995), "Option Contracts and Renegotiation: A Solution to the Hold-Up Problem", RAND Journal of Economics, 26, No. 2, 163-179.

Nöldeke, G. and K. M. Schmidt (1998), "Sequential Investments and Options to Own", RAND Journal of Economics, 29, No. 4, 633-653.

Paul, J. M. (1992), "On the Efficiency of Stock-based Compensation", Review of Financial Studies, 5, No. 3, 471-502.

Repullo, R. and J. Suarez (1999), "Venture Capital Finance: A Security Design Approach", mimeo., CEMFI.

Rogerson, W. P. (1997), "Intertemporal Cost Allocation and Managerial Investment Incentives: A Theory Explaining the Use of Economic Value Added as a Performance Measure", Journal of Political Economy, 105, No. 4, 770-795.

Sloan, R. G. (1993), "Accounting Earnings and Top Executive Compensation", Journal of Accounting and Economics, 16, 55-100.

Walking, R. A. and M. S. Long (1984), "Agency Theory, Managerial Welfare, and Takeover Bid Resistance", RAND Journal of Economics, 15, No. 1, 54-68.

Williamson, O. E. (1985), The Economic Institutions of Capitalism, New York: Free Press.

Yermack, D. (1995), "Do Corporations Award CEO Stock Options Effectively?", Journal of Financial Economics, 39, 237-269. 